\title{
Lessons Learned During the COVID-19 Pandemic to Strengthen TB Infection Control: A Rapid Review
}

\author{
Helena J. Chapman, ${ }^{a}$ Bienvenido A. Veras-Estévez ${ }^{b}$
}

\section{Key Findings}

Current challenges in TB control efforts, such as an unprepared public health system leadership and infrastructure and an overwhelmed health care workforce, will require novel approaches, practices, and renewed political commitment to maintain sustainable TB programs.

We described proposed recommendations that may strengthen health system preparedness for optimal TB control across low- and middle-income countries:

- Ensuring leadership and governance for sustainable national health care budgets

- Building networks of community stakeholders

- Supporting high-quality health care workforce training and safe workplace environments

- Using digital health interventions for TB care

\section{Key Implications}

- National health systems should develop national policies that promote integral, patient-centered TB care, facilitate the implementation of ethical community interventions, support operational research, and allow the integration of appropriate eHealth applications.

- Program managers who understand challenges in TB prevention and control with coexisting health priorities can serve as instrumental leaders and patient advocates to deliver high-quality and sustainable TB care that leads to achieving targets of the End TB Strategy.

\footnotetext{
a Department of Environmental and Occupational Health, Milken Institute School of Public Health, George Washington University, Washington, DC, USA.

${ }^{b}$ Facultad de Ciencias de la Salud, Universidad Católica del Cibao, La Vega, Dominican Republic.

Correspondence to Helena Chapman (hichapman@gwu.edu).
}

\section{ABSTRACT}

Introduction: Over the past 5 years, substantial global investment has resulted in reduced TB incidence rates by $9 \%$ and mortality rates by $14 \%$. However, the coronavirus disease (COVID-19) pandemic has hindered access and availability of TB services to maintain robust $T B$ control. The objective of this rapid review was to describe the challenges to be addressed and recommendations to strengthen health system preparedness for optimal TB control across low- and middle-income countries during and after the COVID-19 pandemic.

Methods: Five databases were used to systematically search for relevant articles published in 2020. The 5-step framework proposed by Arskey and O'Malley and adapted by Levac et al. guided the review process. Thematic analysis with grounded theory principles was used to summarize themes from selected articles and integrate analyses with barriers reported from authors' previous TB research.

Results: Of the 218 peer-reviewed articles, 20 articles met the inclusion criteria. Four emerging themes described challenges: (1) unprepared health system leadership and infrastructure, (2) coexisting health priorities, (3) insufficient health care workforce support for continued training and appropriate workplace environments, and (4) weak connections to primary health centers hindering community engagement. Four recommendations were highlighted: (1) ensuring leadership and governance for sustainable national health budgets, (2) building networks of community stakeholders, (3) supporting health care workforce training and safe workplace environments, and (4) using digital health interventions for TB care.

Conclusions: National health systems must promote patientcentered TB care, implement ethical community interventions, support operational research, and integrate appropriate eHealth applications. TB program managers and primary care practitioners can serve as instrumental leaders and patient advocates to deliver high-quality and sustainable TB care that leads to achieving the targets of the End TB Strategy.

\section{INTRODUCTION}

O $\mathrm{f}$ respiratory infections, TB is the leading cause of global morbidity and mortality, causing 10 million new TB cases and 1.4 million TB deaths in $2019 .{ }^{1}$ TB is spread through aerosol droplets, including those smaller than 5 microns, infected with $M$. tuberculosis from an infected individual to a susceptible individual. Onethird of the global population, which is estimated to have an asymptomatic $M$. tuberculosis infection, has a $5 \%-10 \%$ risk of developing $\mathrm{TB}$ disease during their 
lifespan. ${ }^{2}$ With substantial global investment and political commitment over the past 5 years, TB incidence and mortality rates have continued to decrease by $9 \%$ and $14 \%$, respectively. ${ }^{1}$ To minimize disease transmission, strict adherence to evidencebased infection control and prevention measures are recommended in clinical and community settings. $^{3}$

The End TB Strategy has set ambitious milestones for 2025 and targets to end TB by $2035 .{ }^{4}$ Three pillars place precedence on expanding patient-centered TB prevention and control efforts, forming policies and multisector collaborations across communities and public and private sectors, and ensuring continued attention on scientific research innovations for TB care. ${ }^{4}$ However, these robust efforts have been redirected to support the coronavirus disease (COVID-19) response measures. Economic and human resources for health have been diverted to emergency care and contact tracing of COVID-19 patients, and laboratories have been repurposed for COVID-19 diagnostic testing. ${ }^{5}$ As a result, health care services for infectious diseases and comorbidities of significant burden-like TB, HIV/AIDS, and malaria-diminished, ${ }^{5}$ and citizens were fearful to seek TB diagnostic and treatment services. ${ }^{6}$ During the Ebola virus disease outbreak in West Africa in 2014-2015, similar observations were reported, such as reductions in TB, HIV, and malaria case notifications and treatment, reductions in health care utilization including vaccination coverage, and the breakdown of community cohesion due to fear, apprehension, and socioeconomic impacts. ${ }^{7-9}$

Health systems should recognize the syndemic effects of TB and COVID-19 and analyze 3 factors for best clinical and community management practices of competing health priorities. First, the social determinants of health draw attention to the impact of social environments (e.g., education and income), physical environments (e.g., residence and transportation), and access and quality of health care services, including access to broadband internet. ${ }^{10,11}$ Second, the One Health concept promotes the development of multidisciplinary collaborations to advance clinical and research applications focusing on the human-animalenvironment nexus. ${ }^{12,13}$ Third, the "knowledgeaction" gap can result from limitations in the access of up-to-date scientific knowledge (e.g., health care professions curricula and continuing education), health system infrastructure (e.g., financial resources and surveillance programs), and social environments (e.g., access to health care services and influence of news sources). ${ }^{14,15}$ Hence, the primary health care workforce can contribute to public debates and community campaigns, develop patient education materials on pressing health issues, ${ }^{16}$ and lead efforts to implement evidencebased findings that can optimize clinical, educational, and research practices related to TB care.

To date, numerous countries have reported reduced TB case notifications during the COVID-19 pandemic, reflecting the importance of "The Clock is Ticking" theme for World TB Day 2021. ${ }^{17,18}$ Over the next 5 years, modeling estimates depict that countries with high TB burden will report up to $20 \%$ increased TB mortality or 1.4 million TB deaths, ${ }^{17,19}$ which will negatively impact the End TB Strategy timeline. ${ }^{20}$ In this article, we summarize encountered challenges to be addressed and proposed recommendations from the literature that can strengthen TB prevention and control efforts during and after the COVID-19 pandemic. Moving forward, national health systems can integrate these recommendations into future practices and policies that strengthen health care service delivery, health care professions education, and research capacity related to TB care.

\section{METHODS}

A rapid review was conducted to review the current literature, identify gaps, and synthesize findings, ${ }^{21,22}$ related to challenges and recommendations for TB prevention and control in low- and middle-income countries. We used the 5-step framework proposed by Levac et al., ${ }^{23}$ which was adapted from Arksey and O'Malley, ${ }^{24}$ in our search strategy: (1) identify the research Health systems question; (2) identify relevant studies; (3) select should recognize studies, (4) chart the data; and (5) collate, summa- the syndemic rize, and report the results. ${ }^{23,24}$ The research questions were: (1) What are the existing challenges in TB prevention and control efforts during the COVID-19 pandemic? and (2) What are the proposed recommendations that can strengthen TB prevention and control efforts during and after the COVID-19 pandemic? This search was simultaneously integrated with findings reported from a previous qualitative study that examined challenges in TB prevention and control in a middle-income country, the Dominican Republic. $^{25-27}$

\section{Search Strategy and Selection Criteria}

On January 10, 2021, 2 authors (HJC, BAV) searched 5 databases (PubMed, Scopus, Web of Science, EBSCO Academic Search Premier, SciELO Citation Index). They used the terms "COVID-19," 
"coronavirus," "health systems," and "tuberculosis," to include original articles, reviews, commentaries, and letters, published between January 1, 2020, and December 31, 2020. After removing duplicate articles, authors independently reviewed each abstract and included articles that described the impacts of TB control efforts during the COVID-19 pandemic and proposed recommendations to strengthen health system efforts for TB control. If any disagreement occurred, authors discussed the abstract until consensus was finalized. Articles written in languages other than English were not excluded.

Articles were excluded if they did not include content related to TB and COVID-19, if clinical aspects of TB and COVID-19 management were described or if the focus deviated from the impact of COVID-19 on TB prevention and control efforts of the health system. Authors incorporated relevant citations from selected articles in the analysis. The article screening and selection process is shown in Figure 1.

\section{Data Extraction and Analysis}

After full-text review, authors used the matrix method, with paper trail, documents, review matrix, and synthesis folders, to extract data from each article. ${ }^{28}$ Data included the country or continent focus, study objective, and main summary points related to challenges to overcome and recommendations for $\mathrm{TB}$ prevention and control.

After compiling this information, authors used a qualitative thematic analysis applying grounded theory principles ${ }^{29}$ to identify themes or patterns from selected articles and explore the connections between existing challenges and proposed recommendations to improve TB prevention and control. The 6-step approach of Braun and Clarke ${ }^{30}$ guided the analysis, where authors expanded upon the final themes identified from previous TB research to examine health care workers' perceived barriers to adherence to TB prevention measures in the Dominican Republic. ${ }^{25-27}$ Authors independently reviewed the initial codes

FIGURE 1. Article Selection Process for a Rapid Review on TB Control Efforts During and After the COVID-19 Pandemic

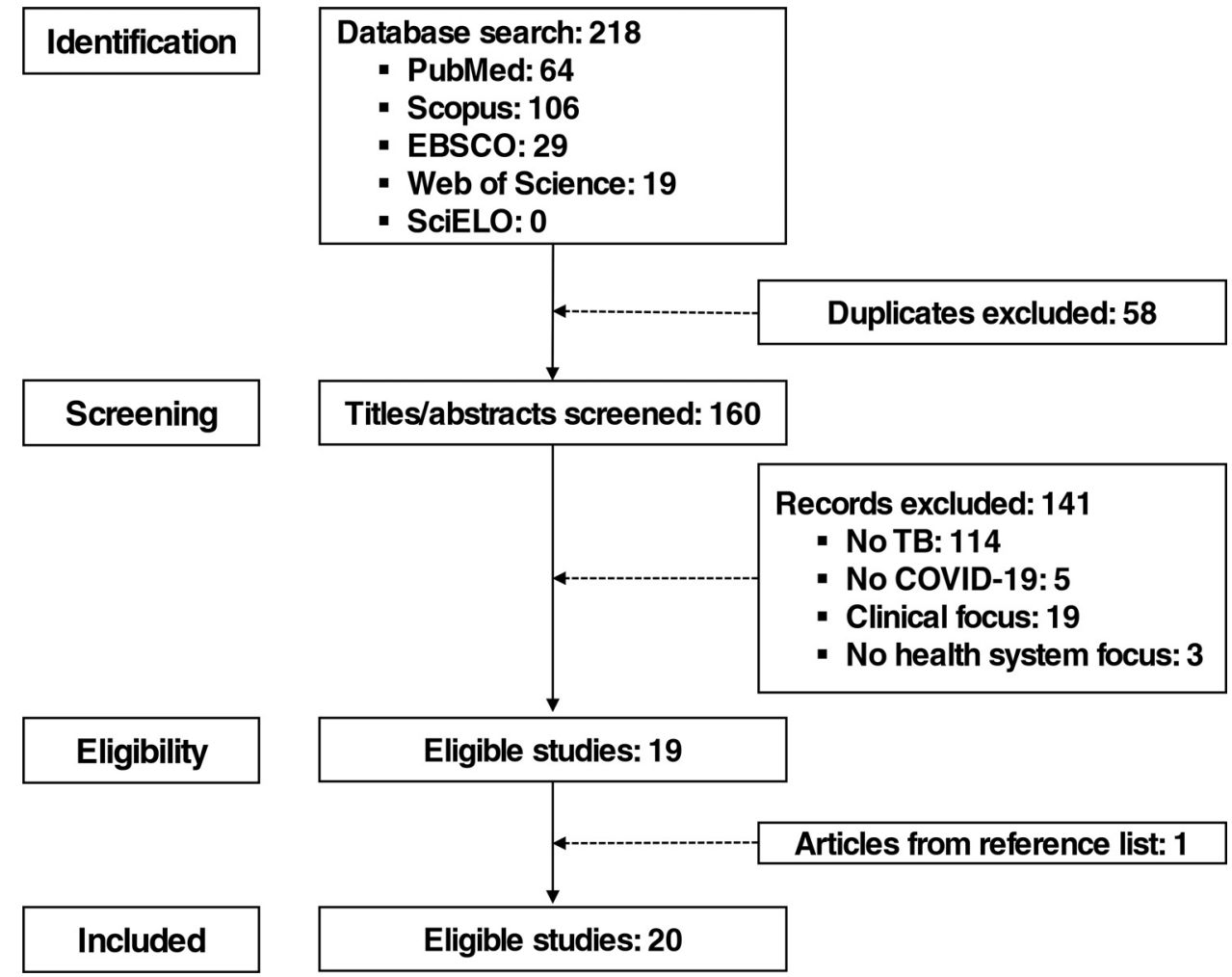


and extracted information to support and expand their meaning. They jointly reviewed and agreed on all final codes, compiled them into relevant themes, and developed a conceptual model.

\section{RESULTS}

The search yielded 218 articles, and after $58 \mathrm{du}$ plicate articles were removed, 160 titles and abstracts were reviewed by both authors. Of the 160 articles, 19 articles met the inclusion criteria, and 1 additional article was added from the manual reference search of these articles. Of the 20 included articles, articles described the TB burden in Africa $(n=8)$, Asia $(n=2)$, and the world $(n=10)$. Article types included 4 letters, 9 perspectives, 5 reviews, and 2 original research articles. Emerging themes from selected articles were identified as existing challenges to be addressed and proposed recommendations to strengthen TB prevention and control efforts (Figure 2).

The characteristics of each article, including proposed recommendations to strengthen TB control efforts during and after the COVID-19 pandemic, are shown (Table 1 and Supplement).

\section{Existing Challenges in TB Prevention and Control}

Four emerging themes on existing challenges in TB prevention and control efforts are displayed (Table 2).

1. An unprepared public health system leadership and infrastructure was described by limited short-term plans, inadequate funding for highburden diseases, and limited foresight to identify key factors that hinder TB control efforts.

2. Coexisting health priorities were exacerbated with disruptions in routine TB care, limited understanding of how natural emergencies impact established health programs, and lack of oversight on the importance of TB programs.

3. Insufficient health care workforce support for continued training and appropriate workplace environments was impacted by the demanding schedules of health care workers and the need for reassigned roles to meet national requests.

4. Weak connections to primary health centers resulted in interrupted community-based programs that hindered patient-provider interactions on routine health care services and negatively impacted early diagnostics and adherence to management.

FIGURE 2. Conceptual Figure That Incorporates Recommendations to Mitigate Existing Challenges and Improve TB Control

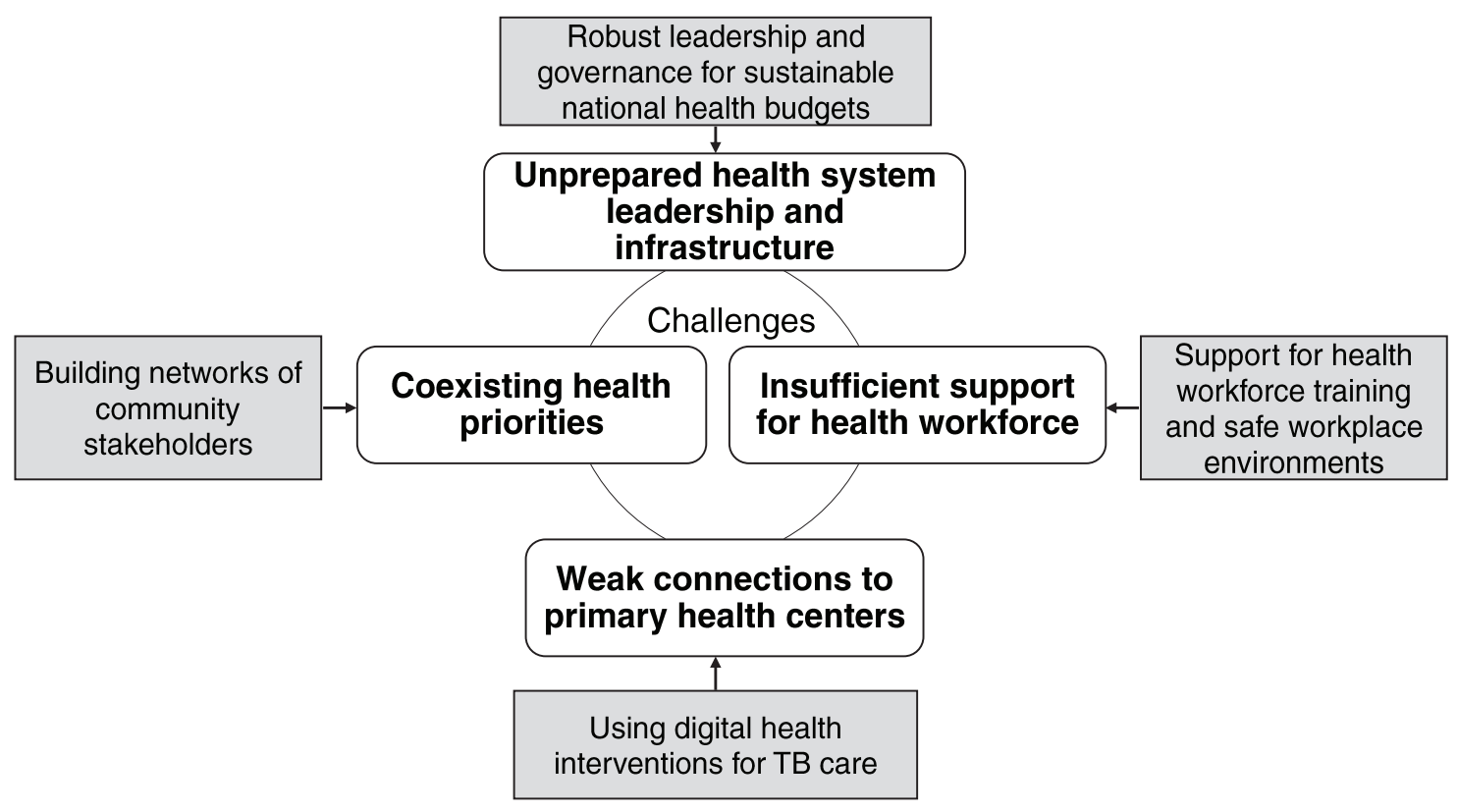

Coexisting health priorities were exacerbated with disruptions in routine TB care, limited understanding of how natural emergencies impact established health programs, and lack of oversight on the importance of TB programs. 
TABLE 1. Selected Articles for the Rapid Review of Literature on Recommendations for TB Prevention and Control During the COVID-19 Pandemic in Low- and Middle-Income Countries

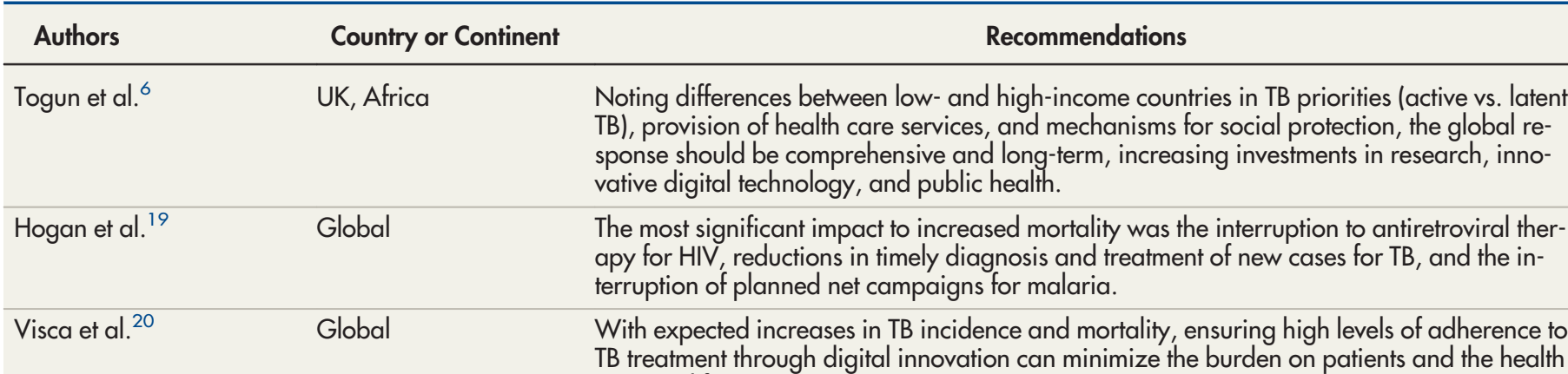
care workforce.

\begin{tabular}{ll}
\hline Adamu et al. $^{31}$ & Africa \\
\hline Alene et al. $^{32}$ & Global \\
\hline Amimo et al. & \\
& Africa
\end{tabular}

COVID-19 response strategies should shift from isolated programs to integrated health system interventions that are connected with existing programs in public and private sectors.

Health systems should aim to maintain routine TB services during the COVID-19 pandemic and hence mitigate the impact of COVID-19 on TB prevention and control programs.

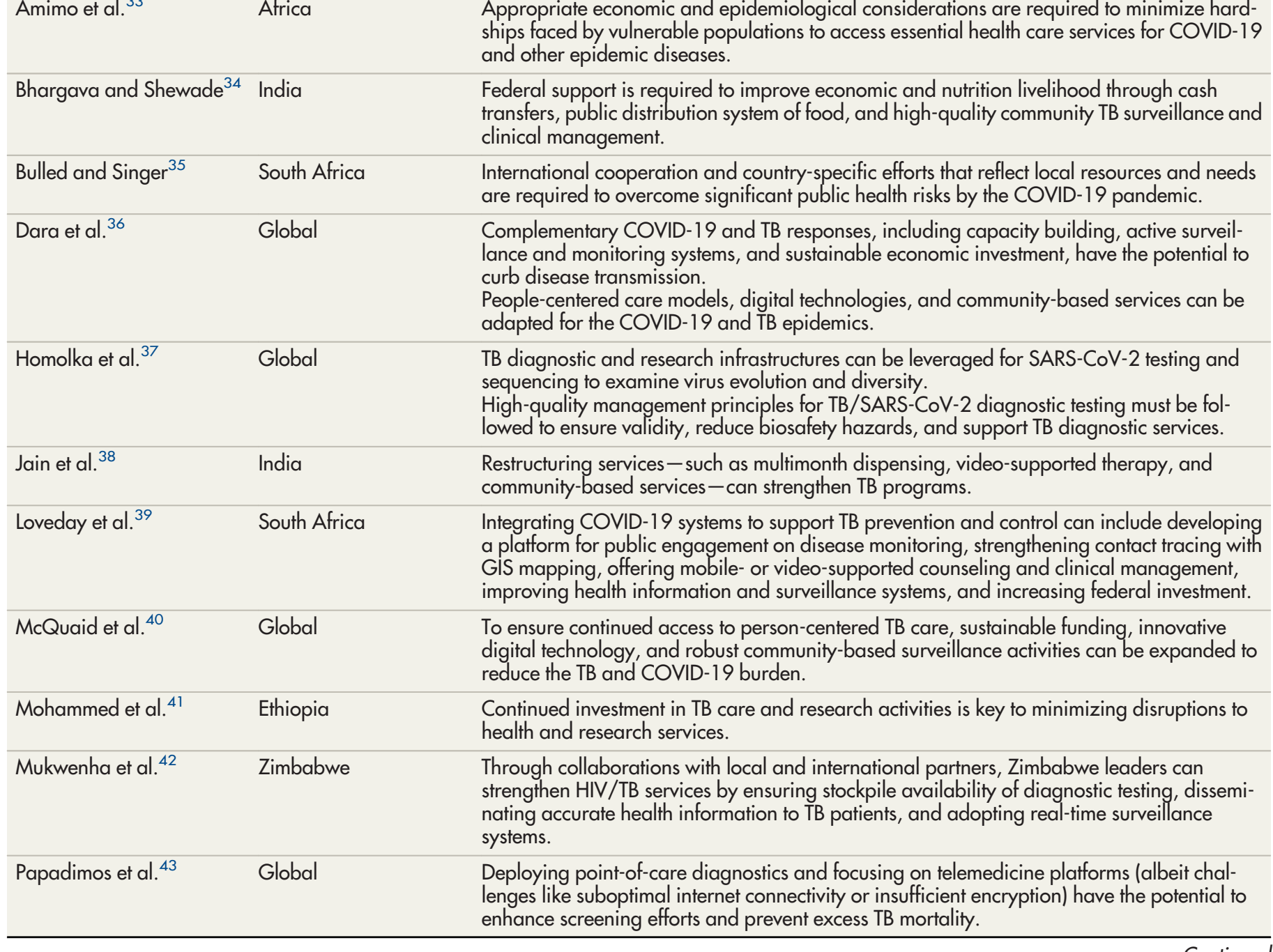

Appropriate economic and epidemiological considerations are required to minimize hardships faced by vulnerable populations to access essential health care services for COVID-19 and other epidemic diseases.

transfers, public distribution system of food, and high-quality community TB surveillance and cinical management. are required to overcome significant public health risks by the COVID-19 pandemic.

lance and monitoring systems, and sustainable economic investment, have the potential to curb disease transmission. adapted for the COVID-19 and TB epidemics. sequencing to examine virus evolution and diversity High-quality management principles for TB/SARS-CoV-2 diagnostic testing must be folowed to ensure validity, reduce biosafety hazards, and support TB diagnostic services. 
TABLE 1. Continued

\begin{tabular}{lll}
\hline \multicolumn{1}{c|}{ Authors } & Country or Continent & \multicolumn{1}{c}{ Recommendations } \\
\hline Sandy et al. ${ }^{44}$ & Zimbabwe & $\begin{array}{l}\text { Urgent responses include increased funding for equipment (PPE, sputum containers), monthly med- } \\
\text { ication supplies, and integrated TB/HIV programs that distribute appropriate health information. }\end{array}$ \\
\hline Saunders and Evans ${ }^{45}$ & Global & $\begin{array}{l}\text { Integrated health care for TB and COVID-19, research investment, community mobilization, } \\
\text { TB-specific social protection, and innovative digital technologies can strengthen TB control } \\
\text { efforts during the COVID-19 pandemic. }\end{array}$ \\
\hline Zachariah et al. ${ }^{46}$ & Global & $\begin{array}{l}\text { Skill-building trainings can support outbreak responses (from data collection to scientific } \\
\text { writing) and surveillance programs. } \\
\text { Investments in health research can strengthen health system resiliency with robust surveil- } \\
\text { lance programs and a prepared workforce. }\end{array}$ \\
\hline Zhou et al. ${ }^{47}$ & South Africa & $\begin{array}{l}\text { Services implemented during the COVID-19 pandemic, such as GIS mapping, can be } \\
\text { repurposed to strengthen TB control efforts. } \\
\text { Reliable health care services for TB and COVID-19 patients are key to reducing stigma and } \\
\text { building trust in health systems. }\end{array}$ \\
\hline
\end{tabular}

Abbreviations: COVID-19, coronavirus disease; GIS, geographic information systems; LMIC, low- and middle-income countries; PPE, personal protective equipment; SARS-CoV-2, severe acute respiratory syndrome coronavirus 2.

\section{Proposed Recommendations to Strengthen TB Prevention and Control Efforts}

Emerging themes on proposed recommendations to strengthen TB prevention and control efforts are listed (Table 3).

\section{Ensuring Leadership and Governance for Sustainable National Health Budgets}

With the risk of national emergency scenarioswhether natural disasters, infectious disease outbreaks, or conflict-nations should implement policies and strategies and allocate funding that strengthens prevention and mitigation efforts for infectious and chronic diseases. ${ }^{48,52,53}$ Political commitment is essential to support core health care services that sustain high-quality point-ofcare diagnostics and treatment plans for TB patients as well as balancing these needs with the coexisting pandemic. ${ }^{19,37,41-43}$ These actions can focus on long-term and comprehensive care for $\mathrm{TB}$ and coexisting priorities like COVID-19. 6,32,36,45

Following the World Health Organization's call that all nations should conduct and utilize research capacity, researchers can investigate key scientific questions raised during coinciding pandemics. ${ }^{37,41,46}$ For example, operational research should be conducted to examine the influence of social determinants of health on TB and COVID-19, vaccine effectiveness and community acceptability, and adherence to recommended pharmaceutical regimens. ${ }^{39,40,45,50}$ These research findings can inform national health priorities, which can provide a framework for the appropriate allocation of economic resources. Supported by appropriate legislature, authorities can recommend actions for the health sector to best distribute resources for current health priorities and unanticipated emergency scenarios. ${ }^{50}$

\section{Building Networks of Stakeholders to Sustain Community Resources}

Forming a network of stakeholders-or community groups comprised of individuals who represent different disciplines but share common goals ${ }^{51}$ — can help identify community needs and health system vulnerabilities related to TB prevention and control. As community stakeholders share approaches and lessons learned, a multisectoral response that aims to reduce TB burden can drive community engagement with families ${ }^{6,31,43,49}$ and support health care workers in facilitating educational activities as a platform to increase TB awareness and reduce stigma. ${ }^{41,45}$ By working with community stakeholders, health leaders can identify high-risk communities of poor health status, including inadequate nutrition, overcrowded living conditions, and unemployment, and advocate for creative solutions to improve public welfare programs. ${ }^{34,35,38}$ These programs can drive national action to offer social protection for TB patients, such as cash transfers or food parcels, and essential psychosocial support. $^{45}$

Coupled with these health promotion activities, community-based research can highlight the use of key epidemiology tools and trends to better understand the transmission of emerging diseases like COVID-19 and emphasize the existing
Community-based research can highlight the use of key epidemiology tools and trends to better understand the transmission of emerging diseases like COVID-19 and emphasize the existing syndemic. 


\section{TABLE 2. Four Emerging Themes on Existing Challenges in TB Prevention and Control Efforts}

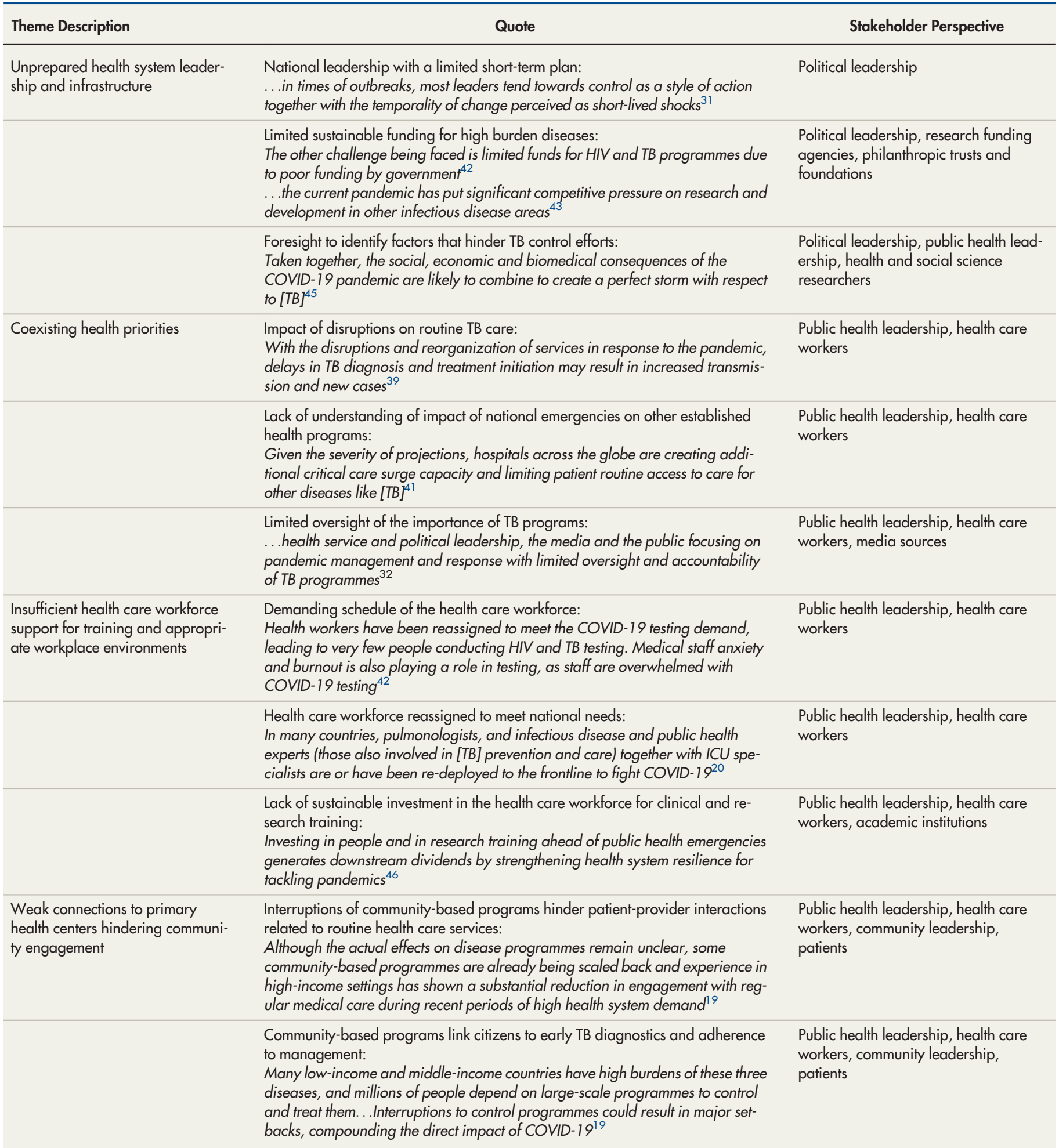

Abbreviation: COVID-19, coronavirus disease. 
TABLE 3. Four Emerging Themes on Recommendations to Strengthen TB Prevention and Control Efforts

Recommendation

Ensuring leadership and governance for sustainable national health budgets

\section{Quote}

Investing in research:

Research, guidance and funding are urgently required to identify, prioritise and deliver those interventions that could best alleviate the impact of COVID-19-related disruptions ${ }^{40}$

... building upstream operational research capacity has generated downstream dividends in strengthening health system resilience for tackling pandemics ${ }^{46}$

Prioritizing community TB care:

Decentralise TB treatment to community health workers and increase access to TB treatment for home-based TB care... support private hospitals, and academic or research centres, to provide $T B$ testing and treatment ${ }^{32}$

Renewing political will to support existing and emerging health priorities: ... strong political will and support for research communities are essential, especially in low- and middle-income settings, to advocate for and allocate resources needed to investigate these coinciding pandemics ${ }^{37}$

Supporting social protection of all citizens:

Provision should also be made for [TB]-specific social protection, which could take the form of cash transfers or food parcels for [TB]-affected households ${ }^{45^{\prime}}$

This [restoring routine TB services] has to be followed by a combination of measures: access to food through universal PDS, direct cash transfers and making gainful employment available 34

Promoting national leadership:

.. it is critically important that political leaders possess appropriate cognitive abilities, procedural hard stops, and advisory capacity to put into place effective solutions $^{43}$

Building networks of community stakeholders

\section{Promoting shared learning among community stakeholders:}

A positive aspect to these two pandemics colliding is that people-communities, public health professionals and policy makers - can learn from each other ${ }^{6}$

Forming multi-sectoral community partnerships:

Non-governmental organisations may partner with governments and national [TB] programmes to mitigate the effects of the COVID-19 pandemic on the provision of biomedical care for [TB]-affected households. This might include sharing diagnostic and laboratory capacity and strengthening caregiver and community health worker roles to support care delivery ${ }^{45}$

Establishing key connections with researchers:

However, as is the case for the capacity of TB diagnostic services, careful planning and close collaboration between the TB, HIV, and COVID-19 research communities will be crucial not to overburden these infrastructures, especially in resource-poor settings ${ }^{37}$

Integrating efforts to build trust and reduce stigma in health system efforts: ... it is therefore important to establish reliable health services and strategies that prioritise care for both TB and COVID-19 patients. This approach will assist in building trust in the health system and allow people to take meaningful measures to keep themselves and their families safe ${ }^{47}$

Supporting high-quality health care workforce training and safe workplace environments
Reinforcing clinical training through short courses:

Provide short-term training for students and health professionals and recruit additional staff to work on TB programs ${ }^{32}$

Building research capacity:

SORT IT teaches multiple and practical skills for activities such as generating and utilizing data, conducting operational research and using evidence to influence policy and/or practice 46

Moreover, with a renewed global focus on active case-finding in TB programs, resources dedicated for COVID-19 community-based research, such as household contact tracing or seroprevalence surveys, could easily be linked to programs to test for TB as well, providing a gateway for training, capacity building, and future TB research ${ }^{37}$
Stakeholder Perspective

Political leadership, public health leadership, research funding agencies, philanthropic trusts and foundations

Political leadership, public health leadership, community leadership

Political leadership, public health leadership, research funding agencies, philanthropic trusts and foundations

Political leadership, public health leadership, community leadership

Political leadership

Public health leadership, health care workers, community leadership, policy makers

Public health leadership, health care workers, community leadership, non-governmental organizations

Community leadership, academic institutions

Public health leadership, community leadership, patients

Public health leadership, health care workers, academic institutions

Public health leadership, health care workers 
TABLE 3. Continued

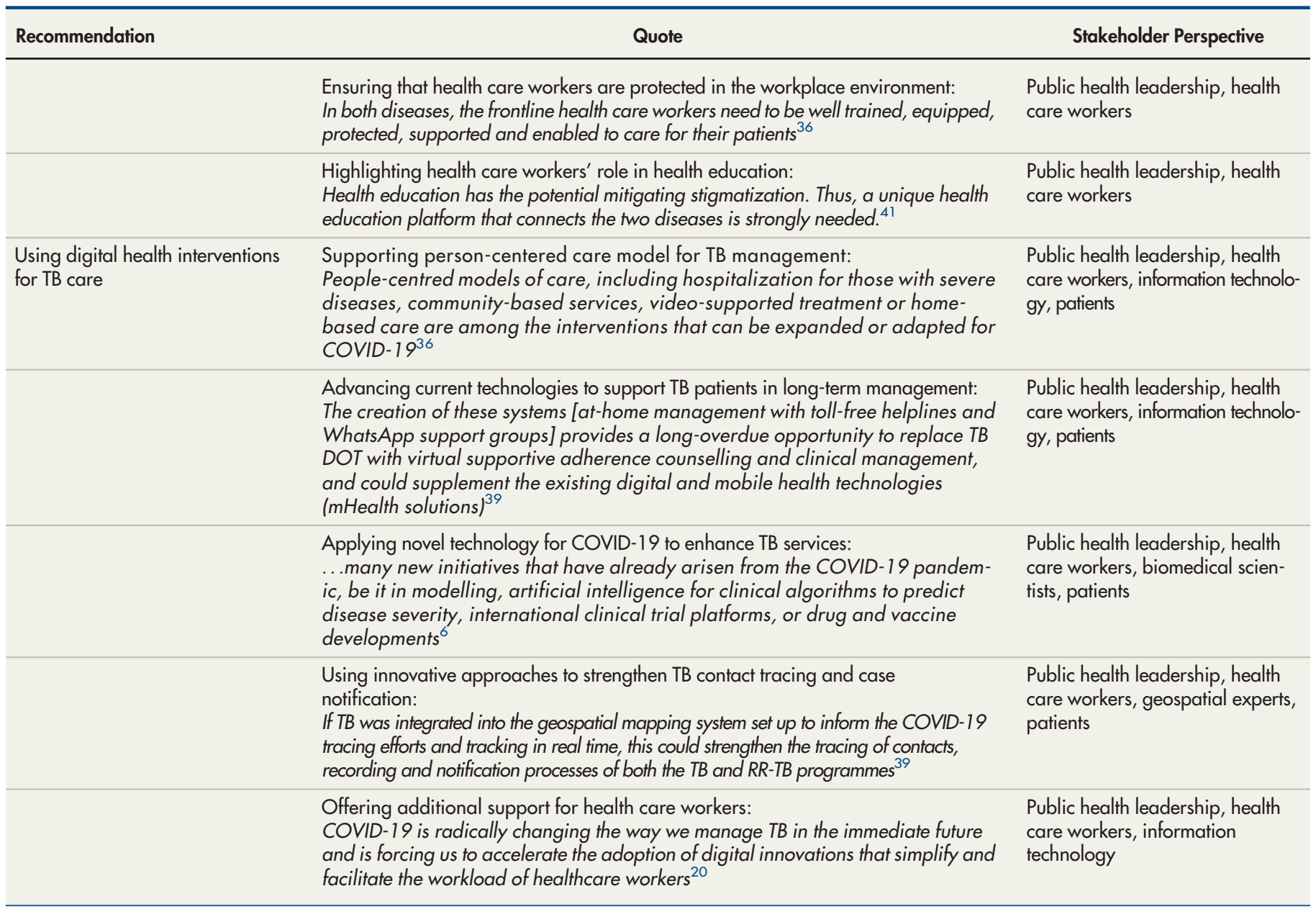

Abbreviations: COVID-19, coronavirus disease; DOT, directly observed therapy; RR-TB, rifampicin-resistant TB.

syndemic and closely linked influencing factors like poverty. ${ }^{45}$ This insight can be applied to current and future plans of TB programs, especially for the diagnosis and management of active and reactivation TB cases. ${ }^{32}$ Health authorities can also streamline public health efforts in COVID-19 and TB control by minimizing duplicated or non-essential approaches and guiding simultaneous surveillance services for rapid response. ${ }^{37,49}$ By identifying po-

Community fora can offer public platforms to share and discuss evidence-based findings that can promote a call to action for policy changes. tential funding partners in the public and private sectors, additional financial resources and equipment can be distributed to health facilities. ${ }^{31,44}$

\section{Supporting High-Quality Health care Workforce Training and Safe Workplace Environments}

A competent health care workforce must be prepared with appropriate knowledge and skills to simultaneously manage endemic and emerging health threats. Health care workers should receive adequate training, appropriate incentives to provide care, and mental health and psychosocial support. $^{36,41}$ Continuing education programs can offer up-to-date information about clinical guidelines, best practices, public health principles, and timely health topics. ${ }^{32}$ This information can offer insight on the influence of social determinants on TB and COVID-19 patients, especially the impact of Comorbidities (e.g., diabetes mellitus), environmental contamination (e.g., air pollution), and economic hardships (e.g., poverty and overcrowded living conditions), and strategies to reduce stigma and discrimination. ${ }^{6,45}$ Community fora can offer public platforms to share and discuss evidence-based findings that can promote a call to action for policy changes. ${ }^{49}$ These key contributions to health systems 
will support the delivery of holistic, patient-centered care services for TB patients.

Health care workers should receive additional skills-based training in field epidemiology with case studies for outbreak investigations and operational research for TB prevention and control. This training can offer skills in identifying priority health issues, literature reviews, connecting with community stakeholders, data collection and analysis, and scientific writing. ${ }^{39,41,49}$ However, with increasing clinical and community health responsibilities-including allocation of staff and resources to new disease priorities-it is important to monitor and evaluate health care workers for mental health stressors and mitigate risk of burnout. ${ }^{39,41}$

\section{Using Digital Health Interventions for TB Care}

Existing electronic health technologies (eHealth), defined as platforms that use information and communication technologies, ${ }^{52}$ have the potential to change the paradigm in TB management. These digital innovations can offer remote support through video-supported therapy and electronic medication monitors for health care workers to guide TB patients through their clinical management, identify and monitor co-morbidities, and encourage treatment adherence. ${ }^{33,36,38,39}$ Mobile health solutions (mHealth) facilitate the delivery of short message service (SMS) and WhatsApp messages as well as geographic information systems (GIS) mapping for direct contact and delivery of test results and health information, ${ }^{39,47}$ especially reaching at-risk communities. ${ }^{33}$ With increased public interest observed during the COVID-19 pandemic, these digital approaches can enhance public engagement on infectious disease monitoring and offer informative fact sheets on multiple infectious diseases. ${ }^{39,44}$ These telemedicine applications, albeit with clear benefits for provider-patient engagement, raise potential questions for health care delivery. Some remaining issues include the ability to ensure patient safety, warrant data privacy and storage, conduct appropriate virtual physical exams, follow limited established protocols, evaluate costeffectiveness, and assess adherence to improve overall equity and efficiency. ${ }^{41,43,45}$ Although comprehensive in-person evaluations cannot be eliminated from acute and chronic patient care, ${ }^{42}$ an integrated approach of in-person consultations and complementary telemedicine applications can pave the future for TB prevention and control efforts.

\section{DISCUSSION}

This is the first known rapid review to examine the existing challenges to be addressed and proposed recommendations to strengthen TB efforts in low- and middle-income countries during and after the COVID-19 pandemic. The End TB Strategy targets were approached in 2020, but not met, with established targets of $20 \%$ decrease in incidence rates (reported $9 \%$ decrease) and $35 \%$ decrease in mortality rates (reported $14 \%$ decrease), with continued challenges in the Americas and African regions. ${ }^{1,53,54}$ Increased attention to TB efforts will be fundamental in the upcoming years to combat the decreased TB notification rates reported during the COVID-19 pandemic; support national policies that prioritize integral, patient-centered TB care; and expand current initiatives to end TB transmission. ${ }^{53}$

Since emerging One Health threats continue to affect the global society, health leaders must be innovative in their contributions to clinical and community settings. Global health systems must be vigilant and prepared to adapt current evidence-based practices to meet societal needs of the next decade. ${ }^{55}$ In this review, selected studies identified challenges in TB control efforts-such as overwhelmed health systems and insufficient support for the health care workforce-that will require novel solutions to improve access and availability of diagnostic and treatment services for TB patients. The use of ground-breaking approaches, data, and practices that can help identify specific challenges, such as country-specific social, economic, and cultural contexts that influence health-seeking behaviors and treatment adherence, ${ }^{35}$ should be considered in maintaining sustainable TB programs.

A robust national health system with skilled leadership, trained health care workforce, health system and research investment, and direct connections with community stakeholders has the potential to achieve the national and international objectives of the Sustainable Development Goals (SDG 3.3) and the End TB Strategy. Political commitment will enhance national preparedness and guarantee an immediate public health response, noting stressors (e.g., dual health priorities) to a well-functioning health system. ${ }^{56}$ Continued investment in operational TB research is essential to identify knowledge gaps, develop sophisticated scientific inquiries, establish methodological and analytical approaches, and implement findings in public health practice. ${ }^{54,57,58}$

Strengthening links with primary care centers and relevant community stakeholders will elucidate

\section{Increased attention to TB efforts will be fundamental in the future to combat the decreased TB notification rates reported during the COVID-19 pandemic, support national policies that prioritize patient- centered TB care, and expand current initiatives to end TB transmission.}


local needs and resources as well as knowledge gaps related to TB care. National programs that advocate for public welfare and social protection for TB patients, including cash transfers, food parcels, housing resources, and psychosocial support, can minimize existing inequities in TB care, alleviate additional psychological stress, and offer indispensable support to TB patients and their families. ${ }^{45,59}$ Partnerships that expand public sector engagement with the private sector (public-private mix) for TB care are essential to meet the targets of the End TB Strategy, including ensuring prompt TB diagnosis and treatment, reducing hardships associated with catastrophic health care costs, and ultimately curbing TB transmission. ${ }^{61,62}$ National health statistics from active surveillance programs provide data on population health risks to authorities for health decision-making activities. Through qualitative research designs, health researchers can capture barriers related to $\mathrm{TB}$ treatment adherence, primary care providers' perspectives on TB control, and social determinants of health. ${ }^{27,62,63}$ Further exploration of the role and acceptance of digital innovations to TB care can be examined among the health care workforce and community members. ${ }^{64}$

Supporting a highly trained health care workforce and safe workplace environments is the responsibility of national health systems, especially with the renewed emphasis on the public-private mix for TB care and prevention. Comprehensive training with required annual continuing education hours for the health care workforce across the public and private sector will reinforce robust technical capacity, offer uniformity across institutions, and expand reach to resource-limited areas. $^{65}$ Appropriate incentives for health care workers, such as financial bonuses, professional recognition, and supervisory positions, have the potential to motivate self-confidence and morale in professional competencies as well as enhance work satisfaction and productivity. ${ }^{66}$ Without this support, the brain drain phenomenon can lead to significant health care workforce shortages as workers migrate to other countries that offer improved working conditions, higher salaries or incentives, personal security, and professional recognition. ${ }^{67}$ Supervisors can also provide mentorship and objective feedback, encouraging health care workers to reach specific milestones in their performance plan. ${ }^{68}$

Digital health interventions can transform TB care by disseminating essential health information, supporting treatment adherence, and encouraging health-seeking behaviors among TB patients. With increased interest and versatility among health professional students, social media platforms have been successfully used to expand health communication efforts during the Ebola virus disease outbreak in West Africa ${ }^{69}$ and guide One Health community field campaigns. ${ }^{70}$ It has the potential to combat the "infodemic"-_defined as the rapid spread of false information-of TB and other stigma-associated diseases like COVID-19 $9^{71}$ as well as streamline operational networks in the public-private mix approach. ${ }^{61}$ Furthermore, telemedicine applications have strengthened provider-patient engagement and TB diagnostic and treatment adherence through text messaging ${ }^{72}$ and computer-aided technology. ${ }^{73}$ Patient safety issues, however, should be evaluated, especially ensuring data security and storage, confirming internet connectivity and related infrastructure, and training health workers in remote technologies. ${ }^{43,73}$ Although the use of broadband internet can substantially enhance the innovative delivery of TB health care services and educational programs, national health systems should identify existing disparities in internet access that can further exacerbate the "digital divide" as a social determinant of health. ${ }^{11,74}$

\section{Limitations}

This study has a few limitations. First, although the authors participated in the data analysis and selected the final themes, they recognize that data may be interpreted in alternative ways. ${ }^{75}$ Second, the study utilized 5 databases for peer-reviewed articles but may have overlooked other relevant papers in the gray literature or other scientific databases. Finally, this study did not evaluate the quality of described challenges and recommendations of selected articles, although this task is not obligatory for rapid reviews. ${ }^{24}$ However, authors did critically analyze the study findings from original research articles and reviews with more substantial detail, than the letters and perspective articles.

\section{CONCLUSION}

This rapid review summarizes areas for improvement in health system preparedness for optimal TB control across low- and middle-income countries. These findings can aid in the development of national policies to promote integral, patient-centered TB care, facilitate the implementation of ethical community interventions, support operational research, and allow the integration of appropriate eHealth applications. By better understanding challenges in TB prevention and control with coexisting health priorities, 
TB program managers and primary care practitioners can serve as instrumental leaders and patient advocates to deliver high-quality and sustainable TB care that leads to achieving targets of the End TB Strategy.

Acknowledgments: The authors recognize the significant contributions of all health care workers, who are dedicated to clinical care, community health, education, health policy, laboratory diagnostics, and research, to combat infectious diseases like TB and COVID-19.

Disclaimer: The views expressed in this article are those of the authors and do not reflect the official policy or position of the George Washington University or the Universidad Católica del Cibao.

Author contributions: Chapman and Veras-Estévez had substantial contributions to the preparation and completion of the article drafts.

Competing interests: None declared.

\section{REFERENCES}

1. World Health Organization (WHO). Global Tuberculosis Report 2020. WHO; 2020. Accessed October 1, 2021. https://www. who. $\mathrm{int/teams/global-tuberculosis-programme/tb-reports/global-}$ tuberculosis-report-2020

2. Zumla A, Raviglione $M$, Hafner R, Fordham von Reyn $C$. Tuberculosis. N Engl J Med. 2013;368(8):745-755. CrossRef. Medline

3. World Health Organization (WHO). WHO Guidelines on Tuberculosis Infection Prevention and Control. WHO; 2019. Accessed October 1, 2021. https://apps.who.int/iris/bitstream/ handle/10665/31 1259/9789241550512-eng.pdf?ua=1

4. World Health Organization (WHO). Implementing the End TB Strategy: The Essentials. WHO; 2015. Accessed October 1, 2021. https://www.who.int/tb/publications/2015/end_tb_essential.pdf? $\mathrm{ua}=1$

5. Ivers LC, Walton DA. COVID-19: global health equity in pandemic response. Am J Trop Med Hyg. 2020;102(6):1 149-1 150. CrossRef. Medline

6. Togun T, Kampmann B, Stoker NG, Lipman M. Anticipating the impact of the COVID-19 pandemic on TB patients and TB control programmes. Ann Clin Microbiol Antimicrob. 2020;19(1):21. CrossRef. Medline

7. Ansumana R, Keitell S, Roberts GMT, et al. Impact of infectious disease epidemics on tuberculosis diagnostic, management, and prevention services: experiences and lessons from the 2014-2015 Ebola virus disease outbreak in West Africa. Int $J$ Infect Dis. 2017; 56:101-104. CrossRef. Medline

8. Elston JWT, Cartwright C, Ndumbi P, Wright J. The health impact of the 2014-15 Ebola outbreak. Public Health. 2017;143:60-70. CrossRef. Medline

9. Desta KT, Kessely DB, Daboi JG. Evaluation of the performance of the National Tuberculosis Program of Liberia during the 2014-2015 Ebola outbreak. BMC Public Health. 2019;19(1):1221. CrossRef. Medline

10. Centers for Disease Control and Prevention (CDC). Establishing a Holistic Framework to Reduce Inequities in HIV, Viral Hepatitis, STDs, and Tuberculosis in the United States. U.S. Department of Health and Human Services, CDC; 2010. Accessed October 1, 2021. https:// www.cdc.gov/socialdeterminants/docs/SDH-White-Paper-2010. pdf

11. Benda NC, Veinot TC, Sieck CJ, Ancker JS. Broadband internet access is a social determinant of health! Am J Public Health. 2020; 110(8): 1123-1125. CrossRef. Medline
12. Centers for Disease Control and Prevention (CDC). One Health. Accessed October 1, 2021. https://www.cdc.gov/onehealth/ index.html

13. Amuasi JH, Walzer C, Heymann D, et al. Calling for a COVID-19 One Health Research Coalition. Lancet. 2020;395(10236):15431544. CrossRef. Medline

14. Haines A, Kuruvilla S, Borchert M. Bridging the implementation gap between knowledge and action for health. Bull World Health Organ 2004;82(10):724-731, discussion 732. Medline

15. Pablos-Mendez A, Shademani R. Knowledge translation in global health. J Contin Educ Health Prof. 2006;26(1):81-86. CrossRef. Medline

16. Porter $G$, Blashki G, Grills N. General practice and public health: who is my patient? Aust Fam Physician. 2014;43(7):483-486. Medline

17. World Health Organization (WHO). WHO Information Note: COVID-19 Considerations for Tuberculosis (TB) Care. WHO; 2021. Accessed October 1, 2021. https://apps.who.int/iris/rest/ bitstreams/1344785/retrieve

18. Deutsch-Feldman M, Pratt RH, Price SF, Tsang CA, Self JL. Tuberculosis - United States, 2020. MMWR Morb Mortal Wkly Rep. 2021;70(12):409-414. CrossRef. Medline

19. Hogan AB, Jewell BL, Sherrard-Smith $E$, et al. Potential impact of the COVID-19 pandemic on HIV, tuberculosis, and malaria in lowincome and middle-income countries: a modelling study. Lancet Glob Health. 2020;8(9):e1132-e1 141. CrossRef. Medline

20. Visca D, Tiberi S, Pontali E, Spanevello A, Migliori GB. Tuberculosis in the time of COVID-19: quality of life and digital innovation. Eur Respir J. 2020;56(2):2001998. CrossRef. Medline

21. Sucharew $H$, Macaluso M. Methods for research evidence synthesis: the scoping review approach. J Hosp Med. 2019;14(7):416-418. CrossRef. Medline

22. Rumrill PD, Fitzgerald SM, Merchant WR. Using scoping literature reviews as a means of understanding and interpreting existing literature. Work. 2010;35(3):399-404. CrossRef. Medline

23. Levac $D$, Colquhoun $H, O^{\prime} B$ Brien KK. Scoping studies: advancing the methodology. Implement Sci. 2010;5(1):69. CrossRef. Medline

24. Arksey H, O'Malley L. Scoping studies: towards a methodological framework. Int J Soc Res Methodol. 2005;8(1):19-32. CrossRef

25. Chapman HJ, Veras-Estévez BA, Pomeranz JL, Pérez-Then EN, Marcelino B, Lauzardo M. Perceived barriers to adherence to tuberculosis infection control measures among health care workers in the Dominican Republic. MEDICC Rev. 2017;19(1):16-22. https:// www.scielosp.org/article/medicc/2017.v19n1/16-22/. Medline

26. Chapman HJ, Veras-Estévez BA, Pomeranz JL, Pérez-Then EN, Marcelino B, Lauzardo M. The role of powerlessness among health care workers in tuberculosis infection control. Qual Health Res. 2017;27(14):2116-2127. CrossRef. Medline

27. Chapman HJ, Veras-Estévez BA, Pomeranz JL, Pérez-Then EN, Marcelino B, Lauzardo M. Health care workers' recommendations for strengthening tuberculosis infection control in the Dominican Republic. Rev Panam Salud Publica. 2018;42:e169. CrossRef. Medline

28. Garrand J. Health Sciences Literature Review Made Easy: The Matrix Method. $4^{\text {th }}$ ed. Jones \& Bartlett Learning; 2013.

29. Creswell JW. Qualitative Inquiry \& Research Design: Choosing Among Five Approaches. 2nd ed. Sage Publications Inc.; 2007.

30. Braun V, Clarke V. Using thematic analysis in psychology. Qual Res Psychol. 2006;3(2):77-101. CrossRef

31. Adamu AA, Jalo RI, Dahiru Al, Wiysonge CS. Implementing COVID19 response within the context of the broader health system: a proposed framework for Africás policy makers. Pan Afr Med J. 2020;35 (Supp 2):46. CrossRef. Medline 
32. Alene KA, Wangdi K, Clements ACA. Impact of the COVID-19 pandemic on tuberculosis control: an overview. Trop Med Infect Dis. 2020;5(3):123. CrossRef. Medline

33. Amimo F, Lambert B, Magit A. What does the COVID-19 pandemic mean for HIV, tuberculosis, and malaria control? Trop Med Health. 2020;48:32. CrossRef. Medline

34. Bhargava A, Shewade HD. The potential impact of the COVID-19 response related lockdown on TB incidence and mortality in India. Indian J Tuberc. 2020;67(4S):S139-S146. CrossRef. Medline

35. Bulled N, Singer M. In the shadow of HIV \& TB: a commentary on the COVID epidemic in South Africa. Glob Public Health. 2020;15 (8):1231-1243. CrossRef. Medline

36. Dara M, Sotgiu G, Reichler MR, Chiang C-Y, Chee CBE, Migliori GB. New diseases and old threats: lessons from tuberculosis for the COVID-1 9 response. Int J Tuberc Lung Dis. 2020;24(5):544-545. CrossRef. Medline

37. Homolka S, Paulowski L, Andres S, et al. Two pandemics, one challenge - leveraging molecular test capacity of tuberculosis laboratories for rapid COVID-19 case-finding. Emerg Infect Dis. 2020;26 (1 1):2549-2554. CrossRef. Medline

38. Jain VK, lyengar KP, Samy DA, Vaishya R. Tuberculosis in the era of COVID-19 in India. Diabetes Metab Syndr. 2020;14(5):14391443. CrossRef. Medline

39. Loveday M, Cox H, Evans D, et al. Opportunities from a new disease for an old threat: extending COVID-19 efforts to address tuberculosis in South Africa. S Afr Med J. 2020;1 10(12):1160-1 167. CrossRef. Medline

40. McQuaid CF, McCreesh N, Read JM, et al; CMMID COVID-19 Working Group. The potential impact of COVID-19-related disruption on tuberculosis burden. Eur Respir J. 2020;56(2):2001718. CrossRef. Medline

41. Mohammed H, Oliira L, Roba KT, Yimer G, Fekadu A, Manyazewal T. Containment of COVID-19 in Ethiopia and implications for tuberculosis care and research. Infect Dis Poverty. 2020;9(1):131. CrossRef. Medline

42. Mukwenha S, Dzinamarira T, Mugurungi $O$, Musuka G. Maintaining robust HIV and tuberculosis services in the COVID-19 era: a public health dilemma in Zimbabwe. Int $J$ Infect Dis. 2020;100:394-395. CrossRef. Medline

43. Papadimos TJ, Soghoian SE, Nanayakkara P, et al. COVID-19 blind spots: a consensus statement on the importance of competent politica leadership and the need for public health cognizance. J Glob Infect Dis. 2020;12(4):167-190. CrossRef. Medline

44. Sandy C, Takarinda KC, Timire C, et al. Preparing national tuberculosis control programmes for COVID-19. Int J Tuberc Lung Dis. 2020;24(6):634-636. CrossRef. Medline

45. Saunders MJ, Evans CA. COVID-19, tuberculosis and poverty: preventing a perfect storm. Eur Respir J. 2020;56(1):2001348. CrossRef. Medline

46. Zachariah R, Dar Berger S, Thekkur P, et al. Investing in operational research capacity building for front-line health workers strengthens countries' resilience to tackling the COVID-19 pandemic. Trop Med Infect Dis. 2020;5(3):118. CrossRef. Medline

47. Zhou S, Van Staden Q, Toska E. Resource reprioritisation amid competing health risks for TB and COVID-19. Int J Tuberc Lung Dis. 2020;24(11):1215-1216. CrossRef. Medline

48. Leaning J, Guha-Sapir D. Natural disasters, armed conflict, and public health. N Engl J Med. 2013;369(19): 1836-1842. CrossRef. Medline

49. Kumar AMV, Harries AD, Satyanarayana S, Thekkur P, Shewade $H D$, Zachariah R. What is operational research and how can national tuberculosis programmes in low- and middle-income countries use it to end TB? Indian J Tuberc. 2020;67(4S):S23-S32. CrossRef Medline
50. World Health Organization (WHO). Key Components of a Well Functioning Health System. WHO; 2010. Accessed October 1, 2021. https://www.who.int/healthsystems/EN_

HSSkeycomponents.pdf

51. O'Brien L, Marzano M, White RM. 'Participatory interdisciplinarity': towards the integration of disciplinary diversity with stakeholder engagement for new models of knowledge production. Sci Public Policy. 2013;40(1):51-61. CrossRef

52. World Health Organization (WHO). WHO Guideline: Recommendations on Digital Interventions for Health System Strengthening. WHO; 2019. Accessed October 1, 2021. https:// www.who.int/publications/i/item/9789241550505

53. Fukunaga R, Glaziou P, Harris JB, Date A, Floyd K, Kasaeva T. Epidemiology of tuberculosis and progress toward meeting global targets - worldwide, 2019. MMWR Morb Mortal Wkly Rep. $2021 ; 70(12): 427-430$. CrossRef. Medline

54. Ranzani OT, Pescarini JM, Martinez L, Garcia-Basteiro AL. Increasing tuberculosis burden in Latin America: an alarming trend for global control efforts. BM Glob Health. $2021 ; 6(3)$ :e005639. CrossRef. Medline

55. Urgent health challenges for the next decade. News release. World Health Organization; January 13, 2020. Accessed October 1, 2021. https://www.who.int/news-room/photo-story/photo-storydetail/urgent-health-challenges-for-the-next-decade

56. Assefa Y, Gilks CF, van de Pas R, Reid S, Gete DG, Van Damme W. Reimagining global health systems for the 21 st century: lessons from the COVID-19 pandemic. BMJ Glob Health. $2021 ; 6(4):$ :e004882. CrossRef. Medline

57. Subbaraman R, de Mondesert L, Musiimenta A, et al. Digital adherence technologies for the management of tuberculosis therapy: mapping the landscape and research priorities. BMJ Glob Health. 2018;3(5):e001018. CrossRef. Medline

58. Nsengiyumva NP, Mappin-Kasirer B, Oxlade O, et al. Evaluating the potential costs and impact of digital health technologies for tuberculosis treatment support. Eur Respir J. 2018;52(5):1801363. CrossRef. Medline

59. Duarte R, Aguiar A, Pinto M, et al. Different disease, same challenges: social determinants of tuberculosis and COVID-19 Pulmonology. $2021 ; 27(4): 338-344$. CrossRef. Medline

60. World Health Organization (WHO). Engaging Private Health Care Providers in TB Care and Prevention: A Landscape Analysis. WHO; 2018. Accessed October 1, 2021. https://www.who.int/tb/ publications/2018/PPMLandscapeAnalysis.pdf

61. Uplekar M. Public-private mix for tuberculosis care and prevention. What progress? What prospects? Int J Tuberc Lung Dis. 2016; 20(1 1):1424-1429. CrossRef. Medline

62. Munro SA, Lewin SA, Smith HJ, Engel ME, Fretheim A, Volmink J. Patient adherence to tuberculosis treatment: a systematic review of qualitative research. PLoS Med. 2007;4(7):e238. CrossRef. Medline

63. Frank J, Abel T, Campostrini S, Cook S, Lin VK, McQueen DV. The social determinants of health: time to re-think? Int J Environ Res Public Health. 2020;17(16):5856. CrossRef. Medline

64. Lee Y, Raviglione MC, Flahault A. Use of digital technology to enhance tuberculosis control: scoping review. J Med Internet Res. 2020;22(2):e15727. CrossRef. Medline

65. Lei $X$, Liu $Q$, Escobar $E$, et al. Public-private mix for tuberculosis care and control: a systematic review. Int J Infect Dis. 2015;34:20-32. CrossRef. Medline

66. Gesme DH, Towle EL, Wiseman M. Essentials of staff development and why you should care. JOncol Pract. 2010;6(2):104-106. CrossRef. Medline

67. Dohlman L, DiMeglio M, Haij J, Laudanski K. Global brain drain how can the Maslow theory of motivation improve our understanding 
of physician migration? Int J Environ Res Public Health. 2019; 16(7): 1 182. CrossRef. Medline

68. Carrico RM, Garrett H, Balcom D, Glowicz JB, Burton J. Infection prevention and control core practices. Nursing. 2018;48(8):22-28. CrossRef. Medline

69. Chapman HJ, Animasahun VJ, Tade AE, Naveed A. Addressing the role of medical students using community mobilization and social media in the Ebola response. Perspect Med Educ. 2016;5(3):186190. CrossRef. Medline

70. Animasahun VJ, Chapman HJ, Oyewole BK. Social media to guide 'One Health' initiatives. Clin Teach. 2020;17(2):214-216. CrossRef. Medline

71. Baneriee D, Meena KS. COVID-19 as an "infodemic" in public health: critical role of the social media. Front Public Health. 2021;9:610623. CrossRef. Medline
72. Yoeli E, Rathauser J, Bhanot SP, et al. Digital health support in treatment for tuberculosis. N Engl J Med. 2019;381(10):986-987. CrossRef. Medline

73. Ugarte-Gil C, Icochea M, Llontop Otero JC, et al. Implementing a socio-technical system for computer-aided tuberculosis diagnosis in Peru: a field trial among health professionals in resource-constraint settings. Health Informatics J. 2020;26(4):2762-2775. CrossRef. Medline

74. Chapman A, Darton TC, Foster R. Managing and monitoring tuberculosis using web-based tools in combination with traditional approaches. Clin Epidemiol. 2013;5:465-473. CrossRef. Medline

75. Miles MB, Huberman AM, Saldaña J. Qualitative Data Analysis: A Methods Sourcebook. 3rd ed. Sage Publications Inc.; 2014

\section{Peer Reviewed}

Received: June 5, 2021; Accepted: September 14, 2021; First published online: November 30, 2021

Cite this article as: Chapman HJ, Veras-Estévez BA. Lessons learned during the COVID-19 pandemic to strengthen TB infection control: a rapid review. Glob Health Sci Pract. 2021;9(4):964-977. https://doi.org/10.9745/GHSP-D-21-00368

(c) Chapman and Veras-Estévez. This is an open-access article distributed under the terms of the Creative Commons Attribution 4.0 International License (CC BY 4.0), which permits unrestricted use, distribution, and reproduction in any medium, provided the original author and source are properly cited. To view a copy of the license, visit https://creativecommons.org/licenses/by/4.0/. When linking to this article, please use the following permanent link: https://doi.org/10.9745/GHSP-D-21-00368 